\title{
Proposed Risk-Informed Seismic Hazard Periodic Reevaluation Methodology for Complying with DOE Order 420.1C
}

Prepared by the INL Seismic Risk-Informed Methodology Independent Panel

March 2016

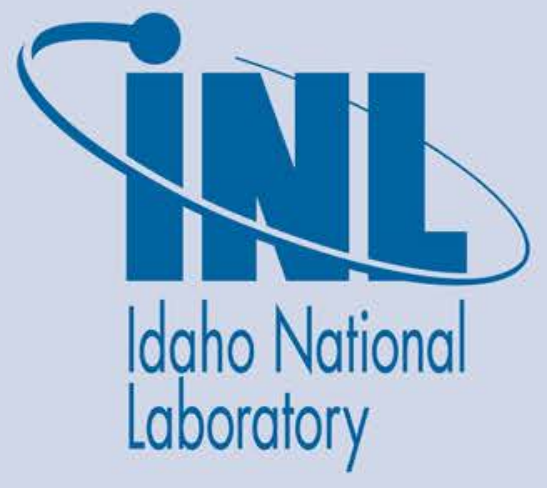

The INL is a U.S. Department of Energy National Laboratory operated by Battelle Energy Alliance 


\section{DISCLAIMER}

This information was prepared as an account of work sponsored by an agency of the U.S. Government. Neither the U.S. Government nor any agency thereof, nor any of their employees, makes any warranty, expressed or implied, or assumes any legal liability or responsibility for the accuracy, completeness, or usefulness, of any information, apparatus, product, or process disclosed, or represents that its use would not infringe privately owned rights. References herein to any specific commercial product, process, or service by trade name, trade mark, manufacturer, or otherwise, does not necessarily constitute or imply its endorsement, recommendation, or favoring by the U.S. Government or any agency thereof. The views and opinions of authors expressed herein do not necessarily state or reflect those of the U.S. Government or any agency thereof. 
INL/EXT-15-36510

Revision 1

\title{
Proposed Risk-Informed Seismic Hazard Periodic Reevaluation Methodology for Complying with DOE Order 420.1C
}

\author{
Prepared by the INL Seismic Risk-Informed \\ Methodology Independent Panel \\ Annie Kammerer \\ Kevin Coppersmith \\ Nilesh Chokshi \\ Robert J. Budnitz
}

March 2016

Idaho National Laboratory

Idaho Falls, Idaho 83415

http://www.inl.gov

Prepared for the

U.S. Department of Energy

Office of Nuclear Engineering

Under DOE Idaho Operations Office

Contract DE-AC07-05ID14517 

Idaho National Laboratory

\title{
Proposed Risk-Informed Seismic Hazard Periodic Reevaluation Methodology for Complying with DOE Order 420.1C
}

\author{
INL/EXT-15-36510 \\ Revision 1 \\ March 2016
}

Approved by:

Approval per 3/15/2016 e-mail to Lalove Foster Mark Cox

$\frac{3 / 15 / 2016}{\text { Date }}$

Approval per 3/15/2016 e-mail to Lalove Foster

Paul Henslee

$3 / 15 / 2016$

Date

Approval per 3/15/2016 e-mail to Lalove Foster Justin Coleman

$3 / 15 / 2016$

Date 
INL/EXT-15-36510

Revision 1 
INL/EXT-15-36510

Revision 1

\section{ABSTRACT}

Department of Energy (DOE) nuclear facilities must comply with DOE Order 420.1C Facility Safety, which requires that all such facilities review their natural phenomena hazards (NPH) assessments no less frequently than every ten years. The Order points the reader to Standard DOE-STD-1020-2012. In addition to providing a discussion of the applicable evaluation criteria, the Standard references other documents, including ANSI/ANS-2.29-2008 and NUREG-2117. These documents provide supporting criteria and approaches for evaluating the need to update an existing probabilistic seismic hazard analysis (PSHA). All of the documents are consistent at a high level regarding the general conceptual criteria that should be considered. However, none of the documents provides step-by-step detailed guidance on the required or recommended approach for evaluating the significance of new information and determining whether or not an existing PSHA should be updated.

Further, all of the conceptual approaches and criteria given in these documents deal with changes that may have occurred in the knowledge base that might impact the inputs to the PSHA, the calculated hazard itself, or the technical basis for the hazard inputs. Given that the DOE Order is aimed at achieving and assuring the safety of nuclear facilities - which is a function not only of the level of the seismic hazard but also the capacity of the facility to withstand vibratory ground motions - the inclusion of risk information in the evaluation process would appear to be both prudent and in line with the objectives of the Order.

The purpose of this report is to describe a risk-informed methodology for evaluating the need for an update of an existing PSHA consistent with the DOE Order. While the development of the proposed methodology was undertaken as a result of assessments for specific SDC-3 facilities at Idaho National Laboratory (INL), and it is expected that the application at INL will provide a demonstration of the methodology, there is potential for general applicability to other facilities across the DOE complex. As such, both a general methodology and a specific approach intended for INL are described in this document.

The general methodology proposed in this report is referred to as the "seismic hazard periodic review methodology," or SHPRM. It uses a graded approach for SDC-3, SDC-4 and SDC-5 facilities that can be applied in any risk-informed regulatory environment once risk objectives appropriate for the framework are developed. While the methodology was developed for seismic hazard considerations, it can also be directly applied to other types of natural hazards. 

INL/EXT-15-36510

Revision 1

\section{FOREWORD}

This report was developed as part of the Independent Panel activities described in INL Seismic Risk Assessment Project Execution Plan PLN-2856 (INL, 2015). According to PLN-2856, the purpose of the Panel is to, "validate, review, and refine the risk-informed methodology through a national level peer review of the proposed process." Although the Panel was originally organized to provide peer review of INL activities, the Panel's activities and focus expanded, resulting in the development of the methodology detailed in this document. The new methodology is intended to provide refinements and additional specificity to the approaches that are currently recommended in DOE Standards and NRC regulatory guidance, as well as to tie hazard reevaluation activities more clearly to the objective of ensuring and demonstrating seismic safety of DOE nuclear facilities. This work has incorporated discussions with the INL Seismic Risk Assessment (SRA) Project team and their stakeholders and the approach was refined based on these interactions. The Panel developed generalized approaches for SDC-3, SDC-4 and SDC-5 facilities, taking into account the increasing potential unmitigated radiological risk consequences associated with those facilities. It is anticipated that the methodology described in this document will be applied to specific INL facilities as part of the SRA project in the near future. Further enhancement of this methodology to incorporate outcomes, lessons, and experience at the INL facility would benefit the application of the methodology at other DOE facilities. 

INL/EXT-15-36510

Revision 1

\section{ACKNOWLEDGEMENTS}

The Independent Panel would like to thank the staff and management of Idaho National Laboratory for the opportunity to participate in this interesting and important project. We would like to thank and recognize Justin Coleman for his leadership and drive in pushing for development of a more rigorous and risk-informed approach to reassessing seismic safety of nuclear facilities under DOE Order 420.1C. We would also like to recognize Suzette Payne for her efforts in advancing the understanding of seismic hazard at the notably expansive and challenging INL site. This document benefitted in many ways from the insights provided by a number of informal external reviewers, including Richard Lee, John Stamatakos, Stephen McDuffie, Donald Moore, and Charles Maggart. Providing a review of the document does not imply endorsement by the reviewers or their respective organizations. 
INL/EXT-15-36510

Revision 1 
INL/EXT-15-36510

Revision 1

\section{CONTENTS}

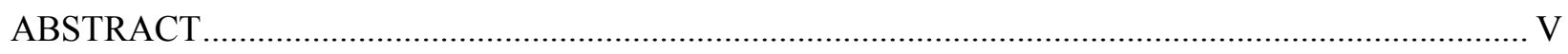

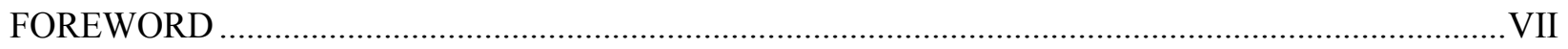

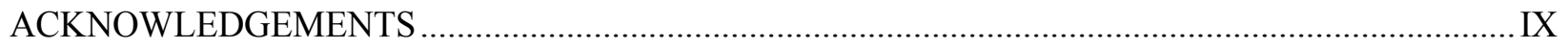

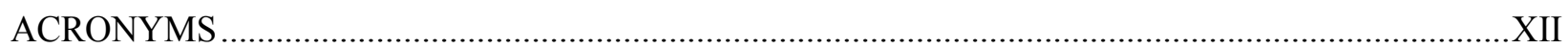

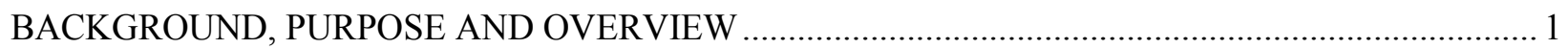

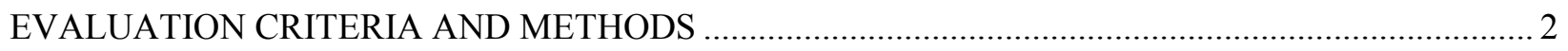

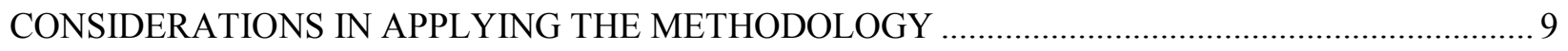

Assessment Team Composition and Peer Review .................................................................. 9

Other Hazard-Related Considerations in Applying this Methodology .......................................... 10

Considerations for Use of New and Existing SPRA and SMA .................................................. 13

PROPOSED GENERALIZED APPROACHES FOR ASSESSING THE NEED FOR HAZARD

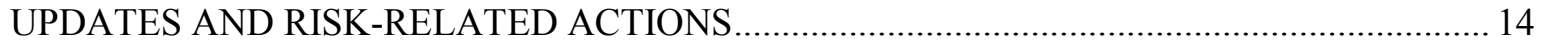

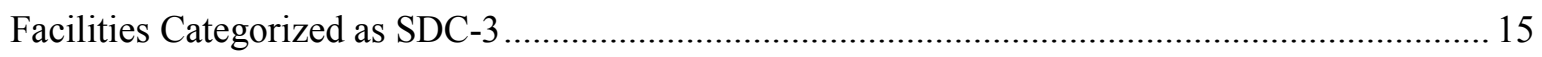

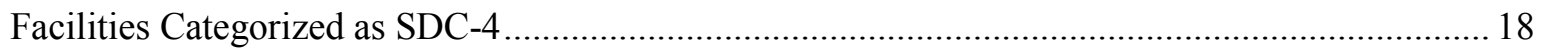

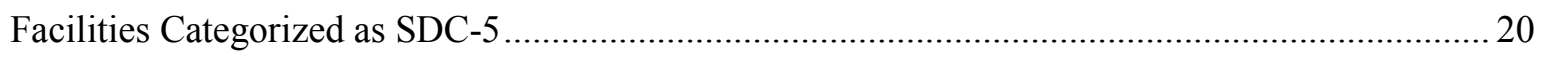

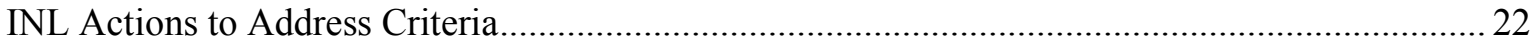

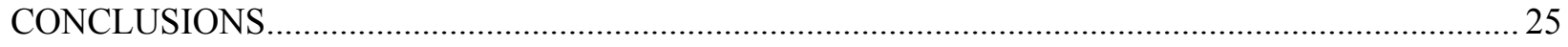

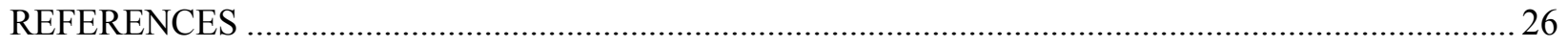

\section{FIGURES}

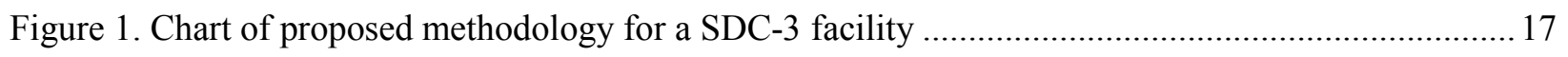

Figure 2. Chart of proposed methodology for a SDC-4 facility ............................................................ 19

Figure 3. Chart of proposed methodology for a SDC-5 facility .......................................................... 21

Figure 4. Chart showing INL activities intended to meet DOE Order 420.1C ...................................... 24

\section{TABLES}

Table 1. Target performance goals, probability ratios, and hazard exceedance probabilities recommended for design of facilities categorized as SDC-3, SDC-4, and SDC-5 ... 6 


\section{ACRONYMS}

AFE

\begin{tabular}{|c|c|}
\hline ANSI/ANS & American National Standards Institute/American Nuclear Society \\
\hline ASCE/SEI & American Society of Civil Engineers/Structural Engineering Institute \\
\hline CEUS SSC & Central and Eastern United States Seismic Source Characterization \\
\hline DBGM & Design Basis Ground Motion \\
\hline DF & Design Factor \\
\hline DOE & Department of Energy \\
\hline GMC & Ground motion characterization \\
\hline GMRS & Ground Motion Response Spectrum \\
\hline HCLPF & High Confidence of a Low Probability of Failure \\
\hline $\mathrm{HCLPF}_{\mathrm{s}}$ & HCLPF Response Spectrum \\
\hline $\mathrm{H}_{\mathrm{D}}$ & Hazard exceedance probability \\
\hline INL & Idaho National Laboratory \\
\hline NPH & Natural Phenomena Hazard \\
\hline NPP & Nuclear power plant \\
\hline NRC & Nuclear Regulatory Commission \\
\hline $\mathrm{P}_{\mathrm{F}}$ & Target performance goal \\
\hline PGA & Peak ground acceleration \\
\hline
\end{tabular}

Annual frequency of exceedance

\section{ASCE/SEI}

CEUS SSC

DBGM

$$
\text { DF }
$$

DOE

\section{GMC}

\section{HCLPF}

$\mathrm{HCLPF}_{\mathrm{s}}$

PSHA

$\mathrm{RG}$
Probabilistic seismic hazard analysis or probabilistic seismic hazard assessment

Regulatory Guide 
$\mathrm{R}_{\mathrm{P}} \quad$ Probability ratio

SDC Seismic design category

SHPRM Seismic hazard periodic review methodology

SL SSHAC Level (as in "SL1", "SL2" and "SL3")

SMA Seismic Margin Assessment

SPRA Seismic probabilistic risk assessment or seismic probabilistic risk analysis

SSC Seismic source characterization

$\mathrm{SSC}_{\mathrm{e}}(\mathrm{s}) \quad$ Structures, systems and component(s)

SSHAC Senior Seismic Hazard Analysis Committee

TI (team) Technical Integration (team)

UHS or UHRS Uniform hazard spectrum or Uniform hazard response spectrum 


\section{Proposed Risk-Informed Seismic Hazard Periodic Reevaluation Methodology for Complying with DOE Order 420.1C}

\section{BACKGROUND, PURPOSE AND OVERVIEW}

Department of Energy (DOE) nuclear facilities must comply with DOE Order 420.1C Facility Safety, which requires that facilities with a designation of seismic design category (SDC) 3 and higher (see ASCE/SEI-43-05 and ANS/ANSI-2.26-2004 (R2010)) must review their natural phenomena hazards $(\mathrm{NPH})$ assessments no less than every ten years and evaluate the need for an update based on significant changes in data, models, methods, and technical bases that would warrant updating the earlier NPH assessment. The earthquake hazard associated with (seismic) vibratory ground motions is the NPH of interest in this report. The Order points the reader to Standard DOE-STD-1020-2012 for criteria to be considered in the 10-year evaluation. In addition to providing a discussion of the applicable evaluation criteria, the Standard references other documents, such as American National Standards Institute/American Nuclear Society Standard ANSI/ANS-2.29-2008 and Nuclear Regulatory Commission (NRC) guidance report NUREG-2117 (NRC, 2012a). These documents provide supporting criteria and approaches for evaluating the need to update an existing probabilistic seismic hazard analysis (PSHA). All of the documents are consistent at a high level regarding the general conceptual criteria that should be considered. However, none of the documents provides step-by-step detailed guidance on the required or recommended approach for evaluating the significance of new information and determining whether or not an existing PSHA should be updated. Further, all of the conceptual approaches and criteria given in these documents deal with changes that may have occurred in the knowledge base that might impact the inputs to the PSHA, the calculated hazard itself, or the technical basis for the hazard inputs. Given that the DOE Order is aimed at achieving and assuring the safety of nuclear facilities-which is a function not only of the level of the seismic hazard but also the capacity of the facility to withstand vibratory ground motions - the inclusion of risk information in the evaluation process would appear to be both prudent and in line with the objectives of the Order.

The purpose of this report is to describe a risk-informed methodology for evaluating the need for an update of an existing PSHA consistent with the DOE Order. While the development of the proposed methodology was undertaken as a result of assessments for specific facilities at Idaho National Laboratory (INL), and it is expected that the application at INL will provide a demonstration of the methodology, there is potential for general applicability to other facilities across the DOE complex. As such, both a general methodology and a specific approach intended for INL are described in this document. The general methodology proposed in this report is referred to as the "seismic hazard periodic review methodology" or SHPRM.

To facilitate the consideration of the risk implications for a range of sites, it is assumed that nuclear facilities of interest have been categorized as SDC-3, SDC-4, or SDC-5. It is assumed that any evaluation methodology must comply with the existing regulatory guidance issued to support the Order (i.e., DOESTD-1020-2012), but can also incorporate the consideration of additional information that pertains to facility risk and safety. Any generalized risk-informed methodology must also account for sites with and without an existing seismic probabilistic risk assessment (SPRA) study. 
The discussion of the evaluation methodology described in the remainder of this document consists of three parts. The first part provides a summary of the seven criteria that are proposed to evaluate the need for an update of an existing PSHA and/or for identifying the need for follow up actions as a result of safety or risk considerations. These various criteria include those currently identified in regulatory standards, but also incorporate additional risk-informed criteria that support ensuring seismic safety. Additional important notes and considerations are also discussed in this part. The second part of this document describes the Panel's proposed approach to using the criteria to make a decision regarding the need to update an existing PSHA for SDC-3, SDC-4, and SDC-5 facilities (i.e., the SHPRM). The third part of the discussion summarizes the activities that are anticipated to develop the information needed to apply the criteria specifically for facilities at the INL Site.

It should be noted that this document describes a risk informed methodology that is intended to be used with qualitative and quantitative risk objectives. The quantification of risk requires both a definition of the unacceptable consequences of interest (e.g., core damage or cancer deaths) and the rate (or frequency) at which the unacceptable outcomes occur considering the entire hazard curve. Currently, the unacceptable outcomes described in DOE documentation are provided as either a deterministic dose (i.e. the possible dose in a specific event without mitigation) or specific performance criteria tied to an appropriately rare ground motion with a specific annual frequency of exceedance (AFE). In the near-term, the available criteria can be used as the basis for developing risk-informed acceptance criteria to be proposed to the appropriate regulatory body while additional risk-informed criteria are being developed.

\section{EVALUATION CRITERIA AND METHODS}

The seven proposed criteria for evaluating the need to update an existing PSHA are described below. As indicated in Figures 1 to 4, these criteria are not simply a set of comparisons applied at the end of exploratory seismic hazard analyses to determine whether or not an update is required. Rather, they are criteria (varied in nature) employed at specific analysis, decision, or comparison points in the process. The first four criteria are given in DOE-STD-1020-2012 and are supported and amplified in ANSI/ANS2.29-2008 and NUREG-2117. These principally address the inputs to the hazard analysis and the hazard results themselves. Criteria \#5 through \#7 are proposed in this methodology to provide additional quantitative risk-focused information to consider in the evaluation of the need for a PSHA update. The use of these seven criteria forms the basis of the reevaluation process, though the timing of the criteria within the process varies for SDC-3, SDC-4, and SDC-5 facilities. The use of these seven criteria to decide whether to update a PSHA, take actions to perform modifications or other risk-related activities, or update a design basis are discussed in the next section.

Prior to discussing the methodology, several assumptions and recommendations are important to note. New construction or a major modification to an existing facility (SDC-3 or higher) will require that a hazard study be conducted using the Senior Seismic Hazard Analysis Committee (SSHAC) Guidelines for a Level $3^{\mathrm{a}}$ study (see NUREG/CR-6372 and NUREG-2117) and that current design and safety/risk assessment methods be employed, thus obviating the need to follow the steps outlined in this document. Likewise, a decision to conduct a SSHAC Level 3 (SL3) study to update the existing PSHA can be made at the outset or at any time, thus obviating the need to further evaluate the viability of the existing hazard study, although risk or safety assessments should still be conducted if appropriate based on the new hazard values calculated. Following the guidance in NUREG-2117 Rev. 1, a site-specific refinement to an

\footnotetext{
${ }^{a}$ The regulatory guidance given in NUREG-2117 makes no distinction between the regulatory assurances provided by a Level 3 versus a Level 4 study. Hence, in the discussions here, we also make no distinction and refer simply to SSHAC Level 3 (SL3) study, which is more commonly used in the US.
} 
existing SL3 regional model can be undertaken using a SL2 process. The resulting study is still considered to meet the SL3 requirement as long as the SL2 refinement does not change the SL3 model in any way, but rather augments it with additional site-specific information (e.g., additional local seismic sources and site response information). This approach is currently accepted by the NRC for licensing of new nuclear power plants using the Central and Eastern Seismic Source Characterization regional model documented in NUREG 2115 (NRC, 2012b) as long as the SL2 refinement is of sufficient quality and scope to meet other NRC siting guidance and criteria.

Because a confident basis is needed for applying the criteria (and that basis should include an assessment of all associated uncertainties), it is recommended that a site-specific enhanced SSHAC Level 1 or 2 study (hereafter noted as "SL1 or SL2 study") be conducted. To enhance the SL1 or SL2 PSHA, the study should include a participatory ${ }^{\mathrm{b}}$ or in-process peer review. If conducted properly and according to regulatory guidance (i.e., NUREG/CR-6372 and NUREG-2117), the hazard assessment activities and the hazard products developed will provide a defensible, well-documented basis to make comparisons with the existing technical underpinnings of the current design or licensing bases for the facility of interest. ${ }^{\mathrm{c}}$ It should be noted that the SL1 or SL2 study will provide a reliable basis for evaluating the need for an update of a PSHA, and will provide an estimate of the updated hazard values to be used in the broader SHPRM activities; however, the SL1 or SL2 study is not, in itself, an update and should not be used for purposes of design or safety assessment.

The DOE Order does not currently require that the evaluation be conducted against a study compliant with the SSHAC methodology. As such, the incorporation of a SL1 or SL2 study in the SHPRM provides a more transparent and rigorous basis from which to perform evaluation activities than has likely been used in the past. The appropriate application of the SSHAC process leads to a model that captures the center, body, and range of the technically defensible interpretations, regardless of the level of the study. The addition of peer review requirements to the SL1/SL2 studies, which is not required in the current SSHAC guidelines, increases confidence in the outcome of the assessment of the need for a new study. However, if a new facility is being designed, or if the outcome of the assessment is that a new licensing basis and/or modifications are needed, the additional regulatory assurance of a SSHAC Level 3 is required in this methodology.

It is assumed in the subsequent discussion that a well-documented PSHA study exists for facilities required to meet the DOE order ${ }^{\mathrm{d}}$. However, this methodology can be applied at any time. The suite of existing PSHA across the DOE complex represents a wide range in terms of their vintages and in terms of the level of documentation and information available. Although DOE-STD-1020-2012 now points to the SSHAC guidelines for new PSHA, to date, DOE has not required that an existing study be replaced if it was not conducted consistent with the SSHAC guidelines.

An existing study that was not conducted using the SSHAC methodology can still provide sufficient documentation, clarity, and quality to allow the reviewer to understand the data, models and methods considered in the study, as well as the technical bases and the resulting model. The existing study should also have the appropriate scope. If the original study has these attributes, the outcomes and hazard results

\footnotetext{
${ }^{\mathrm{b}}$ The terminology "participatory peer review" comes from the SSHAC vernacular and denotes a peer review process that is continual throughout the process, thereby allowing for efficient mid-course corrections when needed. It does not imply that the reviewer participates in the model building or analysis. For more information, see NUREG-2117.

${ }^{\mathrm{c}}$ The readers should refer to NUREG-2117 for information on the differences and relative benefits of SL1 and SL2 studies.

${ }^{\mathrm{d}}$ The exception to this assumption may be sites where multiple facilities choose to coordinate efforts on a site-wide study, as discussed later. If a SSHAC study has been conducted, the reader is further directed to NUREG 2117 for the most recent guidance on reevaluation of an existing study. This guidance is limited in extent in Revision 1 of NUREG 2117, but will be expanded in Revision 2, which is currently under development.
} 
from the SL1 or SL2 study conducted for the evaluation can be compared to the original study with some appropriate degree of confidence. It is, therefore, important that the SL1 or SL2 PSHA study used for the evaluation follows a SSHAC process, as it is this study that anchors the comparison. Additional confidence is gained through the peer review process. If an existing study does not have sufficient documentation to allow for the comparisons in Criteria \#1 through \#4, the outcomes of each of the criteria should be "yes", leading to further evaluation".

All SSHAC studies, regardless of level, are composed of two overarching elements: evaluation and integration. The "evaluation" activities in a SSHAC process include the identification and review of the current data, models, and methods that exist within the larger technical community. After this identification and review has been completed and documented in the SL1 or SL2 study, a solid basis exists for comparing current information with the data, models, and methods that existed at the time the previous PSHA was conducted. Also, because the "integration" activities of a SSHAC process require that the "center, body, and range of technically defensible interpretations" be assessed, regardless of the level of the SSHAC study, the hazard products developed will include a technically defensible estimate of the mean and full distribution of the hazard for subsequent use in the SHPRM methodology.

The seven criteria for evaluating the need for an update of an existing PSHA or other risk and safetyrelated activities are described below and are shown in Figures 1 to 4.

\section{Criterion \#1}

Criterion \#1 requires that all relevant new and updated data, models, and methods be identified, compiled and evaluated to assess how currently available information differs from the information that was evaluated as part of the original PSHA used to develop the design or licensing basis. As discussed above, this may include information from new regional-, local- or site-level studies conducted for the project, as well as other publicly available information. A "yes" response to Criterion \#1 indicates that new data, models and methods that may be significant to the hazard are available. If no new data, models or methods are available, then a "no" response is applied. In this case, the documentation of the evaluation process (including the complete documentation of the SL1 or SL2 PSHA), provides an updated timeline for application of the next 10 year review PSHA assessment cycle consistent with DOE Order 420.1. However, the SL1 or SL2 study is not, in itself, an update and the existing PSHA remains in place.

\section{Criterion \#2}

Criterion \#2 requires that appropriate changes to the inputs to the PSHA model be determined and implemented based on the activities and evaluations associated with Criterion \#1. A "yes" response to Criterion \#2 indicates that the evaluation of new data, models and methods indicated that updated inputs to the PSHA are appropriate. A "no" response to Criterion \#2 indicates that any new data, models and methods available do not support updates to the inputs to the PSHA model. In this case, the documentation of the evaluation process (including the complete documentation of the SL1 or SL2 PSHA), provides an updated timeline for application of the next 10 year review PSHA assessment cycle consistent with DOE Order 420.1. However, the SL1 or SL2 study is not, in itself, an update and the existing PSHA remains in place.

The key inputs to the PSHA to be evaluated are the seismic source characterization (SSC) and/or ground motion characterization (GMC) models. The evaluation must include consideration of the manner

\footnotetext{
${ }^{\mathrm{e}}$ The decision process and use of the criteria is given in the subsequent section entitled Proposed Generalized Approaches for Assessing the Need for Hazard Updates and Risk-Related Actions.
} 
in which aleatory and epistemic uncertainties have been addressed in those models. NUREG-2117 (Rev. 1) calls this assessment an evaluation of the "viability" of the SSC and GMC models. The model's ongoing viability is based on whether or not the technical underpinnings are still technically defensible and whether or not the overall model continues to sufficiently represent the center, body, and range of the technically defensible interpretations.

Important inputs to the hazard model include those required for the site response analysis that determines the amplification of seismic motions due to near-surface materials. A site response analysis determines ground motions at the location and elevation of input to the facility (i.e., the facility's ground motion control point or foundation). In the last decade or so, site response has become increasingly integrated into the PSHA, rather than being performed as an analysis that is separate from and after the PSHA. Site response is now often considered part of the GMC model. In any case, the impact of new and updated data, models, and methods related to site response must be evaluated as part of the evaluation activities performed for Criterion \#2.

\section{Criterion \#3}

Criterion \#3 requires an evaluation of whether or not the technical bases for the hazard have changed, even if the calculated hazard does not indicate a significant change. This is why Criterion \#3 is placed after Criterion \#4 in the SHPRM (See Figures 1 to 3). The Criteria are discussed and numbered in this document consistent with DOE-STD-1020-2012, but it is necessary in practice for Criterion \#4 to be applied before Criterion \#3. The technical bases include the technical arguments and justifications for the hazard inputs and the associated treatment of uncertainties. A "yes" response to Criterion \#3 indicates that the technical bases for the hazard have changed. A "no" response indicates that the technical bases for PSHA inputs have not changed. If the outcome of Criterion \#4 is also "no" (i.e., there is no significant change in the hazard results), the documentation of the evaluation process (including the complete documentation of the SL1 or SL2 PSHA), provides an updated timeline for application of the next 10 year review PSHA assessment cycle consistent with DOE Order 420.1. However, the SL1 or SL2 study is not, in itself, an update and the existing PSHA remains in place.

\section{Criterion \#4}

Criterion \#4 requires a comparison of the original hazard results with results from the SL1 or SL2 model to determine if there are significant changes to the calculated seismic hazard. This requires that the new data, models, and methods (and the associated changes in Criterion \#2) have been accounted for in new hazard inputs that are then used to calculate hazard at the site of interest. A "yes" response to Criterion \#4 indicates that there is a significant change to the calculated seismic hazard. If there is not a significant change to the calculated seismic hazard, the response is "no" and Criterion \#3 is assessed (see Figures 1 to 3 ).

Typically, comparisons of seismic hazard are done using the mean hazard at AFEs of interest for the facility of interest. Appropriate AFEs should be chosen to include the range of AFEs used in quantifying seismic design ground motions and should also consider the range of AFEs likely to be of most significance to the risk assessment. For example, a comparison of the mean hazard curves at least encompassing AFEs from $1 \times 10^{-3}$ to $1 \times 10^{-4}$ could be useful for sites with SDC-3 facilities. Such comparisons of hazard estimates should be made duly considering the precision with which mean seismic hazard is typically calculated. 


\section{Criterion \#5}

Criterion \#5 requires a comparison between the estimated mean hazard, expressed as the uniform hazard response spectrum (UHS or UHRS) at the hazard exceedance probability specified for the SDC category for the facility of interest (see Table 1) and the design basis ground motion (DBGM) that exists for the facility. A "yes" response to Criterion \#5 indicates that the DBGM exceeds the estimated mean hazard from the SL1 or SL2 study (i.e., the design basis ground motion of the facility exceeds the ground motions that would be used as a starting point for determining the design basis for a new facility). For purposes of this comparison, the range and spacing of spectral frequencies described in Section B of NRC RG 1.208 may be appropriate. Discussions related to narrow band exceedance and other comparisonrelated topics in EPRI 2013a might also prove useful in some cases.

As used in this document, the DBGM for a facility is the ground motion level for which the safetyrelated systems have been designed and constructed. Generally it is also the ground motion level for which structures, systems and components $\left(\mathrm{SSC}_{\mathrm{e}} \mathrm{s}\right)^{\mathrm{f}}$ must maintain their safety function. For operating NPPs regulated by the NRC, the DGBM is often referred to as the Safe Shutdown Earthquake ground motion or the Design Basis Earthquake ground motion. For DOE facilities, DOE-STD-1020-2012 refers to the Design Basis Earthquake and this ground motion may also be referred to as the "Authorization Basis Earthquake" ground motion. In any case, the documentation of the comparison made for Criterion \#5 should be clear about the specific DBGM used and the basis of that choice, particularly if multiple ground motion levels are associated with the facility.

In cases where modifications have been made to some, but not all, safety-related $\mathrm{SSC}_{\mathrm{e}} \mathrm{s}$ of a facility (such as when a single "success path" is strengthened), the DBGM used for comparison purposes is the original design basis because this is the ground motion against which all safety-related $\mathrm{SSC}_{\mathrm{e}} \mathrm{s}$ are expected to demonstrate acceptable seismic margin. However, the higher capacities of strengthened $\mathrm{SSC}_{\mathrm{e}} \mathrm{s}$ should be accounted for in any seismic margin assessment (SMA) or SPRA studies.

Table 1. Target performance goals, probability ratios, and hazard exceedance probabilities recommended for design of facilities categorized as SDC-3, SDC-4, and SDC-5

\begin{tabular}{|l|c|c|c|}
\hline \multicolumn{4}{|c|}{ Earthquake Design Parameters } \\
\hline & \multicolumn{3}{|c|}{ Seismic Design Category } \\
\cline { 2 - 4 } & $\mathbf{3}$ & $\mathbf{4}$ & $\mathbf{5}$ \\
\hline Target Performance Goal $\left(\mathbf{P}_{\mathrm{F}}\right)$ & $1 \times 10^{-4}$ & $4 \times 10^{-5}$ & $1 \times 10^{-5}$ \\
\hline Probability Ratio (R) & $\mathbf{4}$ & 10 & 10 \\
\hline Hazard Exceedance Probability $\left(\mathbf{H}_{\mathrm{D}}\right)$ & $4 \times 10^{-4}$ & $4 \times 10^{-4}$ & $1 \times 10^{-4}$ \\
\hline $\begin{array}{l}\text { Note: } H_{D}=R_{P} \times P_{F} \\
\text { This table was reproduced from Table 2-1 of ASCE/SEI-43-05 }\end{array}$ \\
\hline
\end{tabular}

\section{Criterion \#6}

Criterion \#6 is very similar to \#5, but rather than the UHS at the AFE specified for design, the basis for comparison is a Ground Motion Response Spectrum (GMRS), consistent with the description in NRC Regulatory Guide (RG) 1.208 (NRC, 2007), for the applicable SDC level. The GMRS is called the

\footnotetext{
${ }^{\mathrm{f}}$ Note that the acronym $\mathrm{SSC}_{\mathrm{e}} \mathrm{s}$ is used to distinguish the abbreviation for structures, systems, and components from the abbreviation for seismic source characterization, $\mathrm{SSC}$. The acronym $\mathrm{SSC}_{\mathrm{e}}$ is used to denote (the singular) structure, system, or component.
} 
"design response spectrum" (DRS) in ASCE/SEI-43-05. As described in ASCE/SEI-43-05 the GMRS (or DRS) is developed based on a UHS at an AFE of risk significance coupled with "Design Factors" (DF) from ASCE/SEI-43-05 that account for the slope of the overall hazard curve in the region around the AFE of interest. Using the DF as described in ASCE/SEI-43-05, the GMRS may be lower or higher than the UHRS, depending on the slope of the hazard curve. However, the NRC limits the DF to be 1.0 or greater for US NPPs.

In addition to its use in new NPP design, the GMRS has now been used by the NRC as a riskinformed screening measure for the post-Fukushima evaluation of all of the NPPs in the United States (NRC, 2012c). A "yes" response to Criterion \#6 indicates that the DBGM exceeds the GMRS as calculated using current guidance and the results of the SL1 or SL2 results. This means that the ground motion to which the facility was designed exceeds the ground motions that would be used as the design basis ground motion for a new facility using current standards.

In the same way that the GMRS in RG 1.208 was developed to define a level of ground motion for design that will confidently ensure that risk levels of NPPs are within acceptable limits, the GMRS for SDC-3 and SDC-4 categories must achieve the target performance goals for those SDC levels. ASCE/SEI-43-05 section 2.2.1 and Table 2-1 provide the procedure and parameters ( $\mathrm{DF}_{1}$ and $\left.\alpha\right)$, to calculate a DF for SDC-3 and SDC-4 GMRS/DRS, as well as SDC-5.

It should be noted that the technical analyses and information available to support the SDC-3 and SDC-4 design factors is limited. Similarly, the recommended probability ratios $\left(\mathrm{R}_{\mathrm{p}}\right)$ for SDC-3 and SDC-4 facilities were also based on the limited information available at the time ASCE/SEI-43-05 was developed. In effect, the $\mathrm{R}_{\mathrm{p}}$ parameter represents the margin between the hazard at the design AFE and the seismic capacity as represented by the target performance goal. As part of the INL risk studies, SPRAs conducted for NRC-regulated non-reactor facilities will be considered, including fuel cycle facilities and independent spent fuel storage installations. However, there would be significant benefit if a broader effort were undertaken to collect and study information available for SDC-3, SDC-4, SDC-5 facilities to determine the range of both $D F$ and $R_{p}$ values that exists in operating facilities. This is particularly true given the range of facility designs that exist in the DOE complex. This information could also be used to develop clearer and more robust performance criteria for new facilities moving forward.

\section{Criterion \#7}

Criterion \#7 is a comparison of facility-specific risk information and insights against risk-informed criteria and objectives. Because the SHPRM proposed here is intended to be generally applicable to a variety of facility types and regulatory frameworks, the risk objectives used for Criterion \#7 are not specified in this document. In any case, the choice of risk objectives and criteria should be determined and agreed upon, preferably at the start of the overall assessment process, by facility technical staff and management in conjunction with any body that has regulatory responsibility or authority over the facility of interest. As noted elsewhere, risk objectives and criteria should include both quantitative targets and qualitative risk insights. As discussed above, it is important to assess facility performance from a riskinformed - rather than a risk-based - point of view.

An example of risk-informed criteria could be a comparison of the calculated mean risk for the facility against the appropriate target performance goals (for SDC-3, SDC-4, and/or SDC-5 facilities) given in ASCE/SEI-43-05 (see Table 1) at a given AFE. This could be accomplished by combining the updated PSHA ground motions with updated seismic capacities to demonstrate that even though the assessed ground motion values have increased the target performance goal is still met. 
As discussed in ANSI/ANS-2.26-2004; R2010, the assignment of a seismic design category ${ }^{\mathrm{g}}$ to an $\mathrm{SSC}_{\mathrm{e}}$ determined to have a safety function is based on the objective of achieving acceptably low potential risk consequences for the public, the environment, and workers by accounting for the consequences of failure of the facility's $\mathrm{SSC}_{\mathrm{e}}$. Thus, one direct way to satisfy Criterion \#7 for simple facilities that have a limited number of $\mathrm{SSC}_{\mathrm{e}} \mathrm{s}$ and that do not rely on operator actions or have important non-seismic failures is to demonstrate that the $\mathrm{SSC}_{\mathrm{e}} \mathrm{s}$ that are critical to the facility's safety functions meet or exceed the assigned target performance goals on an $\mathrm{SSC}_{\mathrm{e}}$ by $\mathrm{SSC}_{\mathrm{e}}$ basis. Using this approach, the annual probability of loss of safety function (e.g., loss of confinement) for each $\mathrm{SSC}_{\mathrm{e}}$ is compared with the target performance goal $\left(\mathrm{P}_{\mathrm{F}}\right)$ for the particular SDC level of the facility (as provided in Table 1). In applying such an approach for an existing facility, one of the major challenges involves identification of those critical $\mathrm{SSC}_{\mathrm{e}} \mathrm{s}$ whose failures by themselves, or in combination with the failure of other $\mathrm{SSC}_{\mathrm{e}} \mathrm{s}$, could lead to radiological releases. The other related issue is the characterization of realistic failure modes (limit states) of interest for the critical $\mathrm{SSC}_{\mathrm{e}} \mathrm{S}$.

ASCE/SEI 43-05 and ANSI/ANS 2.26 outline the requirements and processes that can be used in the design of a new facility and its $\mathrm{SSC}_{\mathrm{e}} \mathrm{s}$. However, for an existing facility, the use of SPRA or SMA type of approaches, which evaluate integrated response of a facility considering design, as-built, and operational aspects, is very suitable for identifying the critical $\mathrm{SSC}_{\mathrm{e}} \mathrm{s}$ that should be evaluated. This notion has been recognized in the Appendix A of ANSI/ANS-2.26-2004. Although not required to apply the Standard, Appendix A of the Standard states, "...this standard has a risk-informed basis and some applications may benefit from completing a seismic risk assessment, ...". An existing facility would clearly benefit from using a SPRA/SMA type of approach in that these approaches provide a method for identifying the critical $\mathrm{SSC}_{\mathrm{e}} \mathrm{s}$ and, therefore, defensibly limit the scope of $\mathrm{SSC}_{\mathrm{e}} \mathrm{s}$ that should be evaluated.

It is recommended that the above approach for demonstrating compliance with the target performance goals on an $\mathrm{SSC}_{\mathrm{e}}$ by $\mathrm{SSC}_{\mathrm{e}}$ basis be used for simple facilities that have a limited number of $\mathrm{SSC}_{\mathrm{e}} \mathrm{s}$ and that do not rely on important operator actions and do not have important non-seismic failures. This approach provides a straight-forward, conservative approach for quantitatively demonstrating that performance goals in ASCE/SEI-43-05 are met for these types of facilities ${ }^{\mathrm{h}}$. However, if there are compelling reasons (e.g., the use of target approaches is deemed to be too conservative or the regulatory framework requires a direct calculation of dose), SPRA can be used to obtain risk results and insights to demonstrate acceptably low risk. SPRA results allow for comparison with quantitative risk objectives in terms of health effects or radiological doses (or other surrogate measures, such as core damage frequency or large early release frequency in NPPs).

In any case, as noted above, the choice of risk objectives and criteria should be determined and agreed upon, preferably at the start of the overall assessment process, by facility technical staff and management in conjunction with any body that has regulatory responsibility or authority over the facility of interest. Although demonstrating compliance on an SSCe by SSCe basis may be conservative for simple facilities with no important operator actions and no important non-seismic failures, the state-of-the-practice for Level 3 PRA could be overly time and resource intensive for these facilities. Unfortunately, the simplified approach may also limit the risk insights gained by the analysis.

The use of dose criteria at site boundaries may require assessment of additional facilities on the site. Although there are currently no requirements for the consideration of site-wide or multi-facility risk for

\footnotetext{
g The term "seismic design category" and the acronym "SDC" is found in both ANSI/ANS-2.26-2004; R2010 and ASCE/SEI-4305. However, they have different definitions in the two documents and are applied at different levels (on an SSCe basis in ANSI/ANS-2.26-2004; R2010 and on a facility level in ASCE/SEI-43-05).

${ }^{\mathrm{h}}$ Other qualitative risk objectives may be identified in conjunction with the quantitative performance criteria.
} 
any nuclear facilities globally, and general guidance is only now being developed by the International Atomic Energy Agency, this methodology can be enhanced in the future to incorporate risk from multiple facilities.

As facilities become more complex and incorporate operator action, important non-seismic failures, higher levels of redundancy and other elements, the application of SPRA or SMA approaches becomes a necessity. The considerations involved in utilizing an existing SPRA and SMA or performing a new study are discussed later.

Although the above discussion points to use of a quantitative target performance goal as a criterion in some cases, experience in the evaluation of seismic risk for NPPs has led to the important distinction between "risk-informed" and "risk-based" decision-making. A risk-informed process is one that considers quantitative estimates of risk as providing useful information, but does not place strict reliance on the numerical results in determining compliance or lack of compliance with quantitative risk goals. Rather, the quantitative results are combined with other risk insights, such as examination of the major contributors to the risk and associated accident sequences, to inform decisions that use the risk results. Accordingly, the methodology given in this report follows a risk-informed approach to the use of the calculated risk in the decision processes for various SDC levels.

\section{CONSIDERATIONS IN APPLYING THE METHODOLOGY}

\section{Assessment Team Composition and Peer Review}

Throughout the process, the assessment of the available information against the criteria will require the application of engineering and scientific judgment by experts knowledgeable in the applicable fields. For example, judgment must be applied in determining whether or not the technical basis of a new PSHA model is sufficiently different from the basis of the existing model to require an update or replacement (Criterion \#3); in considering the importance of a small, narrow-band exceedance when comparing new hazard information against the DBGM (Criteria \#5 and \#6); and in assessing the facility-specific risk information and insights against performance and risk-informed criteria (Criterion \#7).

Because of the significant role of expert judgment in the evaluation process, performing a SL1 or SL2 PSHA study is recommended at the start of the process. Current regulatory guidance given in NUREG/CR-6732 and NUREG-2117 provides general guidance for conducting Level 1 and 2 studies, and more detailed implementation guidance for these study levels is currently being developed in a revision to NUREG-2117. It is recommended that the Technical Integration (TI) team ${ }^{\mathrm{i}}$ for the hazard study needs to be - at a minimum - a small team of people in order to ensure that various technical disciplines are sufficiently represented and that all viewpoints, data, models, and methods are identified and appropriately incorporated. Additionally, an in-process or participatory peer review of the PSHA is also strongly recommended in this proposed methodology.

The risk assessment elements of the process should similarly be conducted by qualified individuals that - as a team - have the appropriate knowledge and experience in walk-downs, fragility assessments, and system/risk modeling. Similarly, an in-process peer review is recommended for the risk analysis studies. Information on the conduct of and topics of peer review is found in various guidance documents

\footnotetext{
${ }^{\mathrm{i}}$ The reader is pointed to Section 3.6.4 of NUREG-2117 for a definition and broader discussion of the Technical Integrator role.
} 
(NRC, 2012d; EPRI, 2013a; DOE, 2013; and ASME/ANS, 2013). Risk assessment peer review should (at a minimum), include a review of the overall approach or type of study conducted and the methodology applied, the study's ability to demonstrate that the risk/performance objectives are met, the technical elements of the study, and the outcomes.

When the SHPRM defined in this report is implemented at the project-level or program-level, it is recommended that the overall process be peer reviewed to help ensure that the overall risk-informed decision process achieves its objectives. The SHPRM peer reviewers should be appointed by and report to the sponsor of the project. They should address both the process and technical aspects associated with hazard (including site response), fragilities, systems modeling, and integrated risk-informed approaches and decision-making. The SHPRM peer review team members should have the appropriate technical backgrounds and have an understanding of (and experience with) the integration between the disciplines and risk-informed decision-making. It would be appropriate for some of the SHPRM peer review team members to also act as reviewers for the individual technical elements (e.g., a hazards expert could act as a reviewer for the initial SL1 or SL2 study, SPRA experts could act as risk assessment peer reviewers). However, it would be beneficial for at least one peer review team member to focus principally on interfaces among technical disciplines, discipline integration, and risk-informed methodology. The use of a SHPRM peer review team provides additional regulatory assurance, and helps to ensure that project objectives are met and that there are not interface issues among the disciplines.

\section{Other Hazard-Related Considerations in Applying this Methodology}

This report describes a proposed risk-informed methodology for evaluating the need for an update of an existing PSHA consistent with the DOE Order. It also describes how risk studies and risk information fit into an overall risk-informed decision making process. However, it does not describe details of the PSHA update or SPRA activities, if needed. The reader is instead referred to other guidance documents focused on these topics. Figure 1, for example, only contains activities associated with the evaluation activities for the facility. It does not include specific details regarding how any resulting PSHA or SPRA studies should be conducted.

It is important to note that the SHPRM described in this report is general, but that its application and the outcomes are site- and facility-specific. For example, the assessment of seismic hazard should be specific to the site and should incorporate all available site information needed to make a meaningful comparison with the existing PSHA and design bases. Likewise, the SDC level for the facility is an important attribute and the activities included in this methodology will vary as a function of the SDC level. In general, because of the higher potential consequences of higher SDC levels, the methodology follows a graded approach to requiring more rigorous analyses and decision steps for higher SDC levels. The risk information that is developed as part of this methodology is applicable to the specific facility analyzed and should not be used to evaluate any other facility.

The SL1 or SL2 study proposed as a starting point is intended to provide a structured, transparent, well-documented and defensible approach for the compilation and evaluation of available information. It also includes integration of the compiled data into new hazard-input models, as necessary, for purposes of understanding the degree to which the existing model reflects current knowledge. If it is determined that a PSHA model update (or replacement) is required, the SL1 or SL2 model is only used to inform the subsequent study; it does not become the new PSHA model. For example, the SL1 or SL2 model is useful for performing the preliminary hazard calculation and sensitivity analysis, as described in Section of 4.8 of NUREG-2117, and the information compiled in the SL1 study can form the foundation of the database of the subsequent study. However, if the need for an update of the PSHA is identified, the SL1 study 
would not be appropriate for use as the updated hazard study or for any associated re-evaluation of the design bases for existing facilities.

Regional models from seismic hazard studies conducted using a SL3 approach (e.g., the CEUS SSC study (NUREG-2115)) are now available for a significant part of the US. The advantage of conducting large-scale regional studies is that they have the potential to benefit significant numbers of sites, enhance consistency, and increase regulatory assurance. For example, the CEUS SSC project and the NGA-East projects are applicable to the entire region of the continental U.S. east of the Rocky Mountains and so provide a high-quality and consistent starting point for a large number of sites regulated by DOE and the NRC. In some cases, the regional model is not part of a facility's existing model, but should be considered along with other new data, models, and methods. Moving forward, these regional models may ultimately also be part of the design or licensing basis for some facilities. In any case, for sites that sit within the regional study zones, the evaluation of the need for an update (or refinement) of the existing PSHA will need to consider the vintage of any existing or new regional study, along with existing or new site-specific information. When assessing a regional study, the degree to which the regional study is periodically reviewed and maintained should be considered because this is an indicator of the degree to which the model continues to adequately represent the center, body and range of the technically defensible interpretations. Any available studies that propose enhancements to the regional model should also be considered.

As anticipated when these studies were commissioned, the use of the models at any given site will need to consider whether local information in the vicinity of the site would require a site-specific "refinement" of the regional model to account for the local information. As discussed in NUREG-2117, these local "refinements" are not revisions of the regional model in the sense that they would in any way negate or change the endorsed regional study. Instead, they augment the regional model (e.g., by adding additional seismic sources or local specificity) to make it appropriate for a specific site ${ }^{j}$. If new data, models, or methods locally would require such a change to the regional model, the regional model can be used as a starting point. However, if any changes are made to the regional model as part of a site-specific study, the resulting model is an entirely new site-specific model and it should be clear that the new model is not a refinement of the regional model. Updates of the regional model must be performed on a regional level with a balanced treatment of all regional data.

An advantage of the existence of a regional model at a given site is that refinements of the regional model can be conducted at lower SSHAC levels. For example, NUREG-2117 (Table 6-1) indicates that refinements of SL3 regional studies should be conducted according the processes described in RG 1.208 and the standards ANSI/ANS-2.27 and 2.29 and can be conducted using SL2 processes. Such refinements of the CEUS SSC study, for example, have been conducted using SL2 processes.

With the passage of time, a site within the study region of a regional PSHA model will need to consider the significance of the new information using the methodology described in this document. If it is determined that the regional study cannot be used as-is, the advantage of having the preexisting regional study as a starting point will be that a good understanding will exist regarding the important technical issues for the hazard at the site and the process of updating the available database will likely be limited to just those data that potentially influenced the regional model, such as the earthquake catalog, and any new information developed in the site vicinity.

Local information should also include data that are important for site response analysis at the particular site of interest. Site response analysis is important for obtaining the necessary inputs for new

\footnotetext{
${ }^{\mathrm{j}}$ In the case of new NPPs, this may be needed to meet the requirements of RG 1.132, and Appendix C of RG1.208.
} 
design bases and may also be important for the development of ground motions for safety reviews. Therefore, the consideration of new data, models, and methods should include information that might have an impact on site response and site-specific ground motion.

This document was developed for the periodic reevaluations conducted to fulfill the DOE Order. However, it can also be applied to the evaluation of new seismic information that comes to light at any time.

A somewhat unique aspect of DOE facilities that are governed by the DOE Order is that they are often hosted by the same DOE site and, therefore, lie within relatively close proximity to other DOE facilities. Although the Order deals with facilities in isolation, there are advantages to conducting sitewide seismic hazard studies. The obvious advantages are potential cost-savings when multiple facilities and sponsors support a single PSHA, and consistency in the elements of the PSHA models from facility to facility. If multiple facilities at a DOE site coordinate a single site-wide study, but the facilities are not all on the same reevaluation timeline, the question arises as to how long the site-wide study is valid before a new SL1 or SL2 study must be conducted. To avoid this issue, facilities with upcoming NPH assessment reviews may want to accelerate their timeline so that as many facilities as possible reestablish a new coordinated timeline. In any case, coordination of efforts would lead to efficiencies and consistency across the site. Because of the importance of site characteristics beneath a facility site, site response analyses would need to be site- and facility-specific.

When applying the SHPRM, or any approach based on the SSHAC methodology, it is important to assess the need for additional data collection efforts early on and to conduct such activities in a timely way to support the evaluation efforts. The SSHAC methodology should never be used to avoid appropriate site investigation activities. NUREG-2117 addresses this topic in a number of places, and discusses it with some level of detail in Section 3.4, Data Collection and Expert Judgment. According to NUREG-2117, "A vitally important issue here, sometimes overlooked in planning large PSHA studies, is that such expert judgment should only be used to identify and quantify the uncertainty that remains after appropriate data collection, compilation, and evaluation activities have been completed." NUREG-2117 goes on to state that,

"If significant data gaps exist, new focused data collection efforts can be considered. Geological data collection and processing can include, for example, field studies, interpretation of remote sensing imagery, geodetic measurements of deformation rates, gravity and magnetic surveys, trenching, and dating of deposits. Seismological investigations can include the collection of historical information related to preinstrumental earthquakes, the collection and reprocessing of seismograms from the early instrumental era, relocation of earthquake hypocenters, the use of improved velocity models and advanced algorithms, and (of course) the installation of additional instruments. Strong-motion data collection and processing activities also can include instrumentation of the site or region (even weak-motion recordings from the site of interest can be of great value) and the geotechnical characterization of recording stations as well as testing of predictive equations using local strong-motion datasets and intensity observations.

Such new data collection activities are important because the expansion of datasets can reduce uncertainty in an assessment... The smaller the uncertainty, the more useful and more robust will be this characterization. Because uncertainty will always be present to some degree, it is very important that it is captured in the assessment. The SSHAC process is designed to assist the analyst in meeting the objective of capturing the state of knowledge and associated uncertainties regarding the seismic hazard at a given location 
at a given point in time. Therefore, multiple-expert assessment should never be used as a substitute for data collection. In other words, the experts in a PSHA should never be used to infer or guess values that could reasonably be measured within the time and budget resource constraints of a project. To do so is a misuse of the SSHAC process."

\section{Considerations for Use of New and Existing SPRA and SMA}

Incorporating the estimated or updated hazard information into either an appropriate existing SPRA or a new SPRA for a facility can provide an estimate of the mean risk for the facility and other risk insights that are necessary to make risk-informed decisions (Standard ASME/ANS RA-Sb-2013, Standard DOE-STD-1628-2013 and NRC, 2009). These risk insights may include information on the $\mathrm{SSC}_{\mathrm{e}} \mathrm{s}$ that are dominant risk contributors, the most risk-significant accident sequences, and the potential consequences. Using an appropriate existing SMA study or performing a new SMA study is also an appropriate alternative to SPRA in some cases. A margin study in this context is an approach used to establish a facility's capability to withstand a seismic event greater than the design basis event ${ }^{\mathrm{k}}$. Considerations for using SMA for each SDC are discussed later in this document.

The use of an existing SPRA or SMA study, in conjunction with new hazard information, is a quick way to determine the impact of the new hazard information on the assessed risk of the facility. An existing study can also be used to assess whether or not there is a need for immediate actions to improve the safety/risk profile of a facility and, if so, which actions may be the most beneficial. However, certain considerations and criteria need to be satisfied in order to use an existing analysis and model. These considerations and criteria are related to the continued validity of the existing model in terms of how well it reflects current conditions of a facility and the model's ability to realistically estimate facility response to the latest ground motion characteristics. For example, EPRI Report 1025287 (EPRI, 2013a) discusses considerations for using an existing SPRA model for SDC-5 facilities. The benefits and disadvantages of using either a new or existing study (either a SPRA or an SMA) in terms of time required to obtain important risk information versus the degree to which the model is up to date and uses modern tools (such that the results could be relied upon) will greatly depend on the nature of a facility and its complexity in terms of the relevant systems and potential number of accident scenarios. For example, a complicated SDC-5 facility, such as an NPP, involves both passive and active systems, and requires the consideration of non-seismic failures and operator actions. In contrast, a risk analysis for a SDC-3 facility may only involve failure of passive components with few potential accident scenarios that affect the risk. In any case, the decision to use an existing study or perform a new SPRA or SMA depends on many factors and requires expert judgment. As a result, this is an area in which in-process peer review is beneficial. This issue is further discussed for each of the SDC levels later in this document.

SPRA directly provides an estimate of the mean risk (along with the uncertainty distribution) for the facility. It also provides other risk insights that are necessary for making risk-informed decisions. Although the focus of a margin study is to establish a facility's seismic capability in terms of a high-

\footnotetext{
${ }^{\mathrm{k}}$ Well established margin approaches (EPRI, 1991; NRC, 1985; and NRC, 2012d) exist for SDC-5 facilities. These approaches provide information regarding a NPPs seismic capability and can be extended in certain conditions to gain some risk insights. For SDC-3 and SDC-4 facilities these concepts will have to be adopted and modified as appropriate. The original margin assessment approaches were developed using insights from SPRAs of NPPs located in Central and Eastern US. Certain considerations are needed for using these approaches at the higher seismicity sites (NRC, 2012d)
} 
confidence low probability of failure (HCLPF) capacity ${ }^{1}$, it can also provide useful information for riskinformed decisions needed to evaluate Criterion \#7. HCLPF capacity is characterized in terms of a response spectrum (herein noted as $\mathrm{HCLPF}_{\mathrm{s}}$ ). One direct way to evaluate Criterion \#7 for simple facilities using an SMA is to compare the $\mathrm{HCLPF}_{\mathrm{s}}$ to the new GMRS. If the HCLPF spectrum envelops the GMRS, then there is a high degree of confidence that the performance target will be met.

Two approaches can be used for SDC-5 facilities to establish a HCLPF. The first approach is called the "success path" approach and is focused on identifying a path (or paths) that can ensure that critical safety functions are maintained under a postulated seismic event that causes ground motions greater than the design basis ground motion. This achieves a "safe shutdown" state in the parlance of the NRC. The second approach, commonly called the "NRC SMA" approach, uses a simplified SPRA-style logic model (composed of event trees and fault trees) to identify potential accident sequences. Accident-level and facility-level $\mathrm{HCLPF}_{\mathrm{s}}$ are established based on analysis of the SPRA-style logic model. Both approaches are viable, and the appropriate choice depends on the nature and complexity of a facility, with the NRC SMA approach being more appropriate for more complex facilities. If an SMA is appropriate for use in the SHPRM, the margin study should have the following attributes:

- The SMA should consider important seismically-induced potential accident initiators.

- The SMA should incorporate non-seismic failures and operator actions, as necessary. The resulting $\mathrm{HCLPF}_{\mathrm{s}}$ should reflect these potential failures. Potential enhancements to seismic safety may result from improving non-seismic failures or making procedural changes.

- The ground motion level used to establish the facility HCLPF should be at the GMRS level or higher.

Results from a SPRA or a well-executed SMA study can be used to determine if an immediate action is needed and, if so, to identify the most safety significant enhancements for consideration. "Interim actions" may also be prudent when new estimates of ground motion are significantly higher than the design basis ground motion and the SPRA or a margin study is yet to be completed. For example, the NRC in its request for information (NRC, 2012b) to the NPP licensees, as part of its implementation of the NRC's Near-Term Task Force Recommendation 2.1, identified the need for consideration of interim actions while detailed SPRA for facilities that screened into additional risk assessments are underway. The approach developed by the nuclear industry (EPRI, 2013b) in response to the NRC request includes identification of one success path that can achieve certain safety functions under one of the most likely seismically-induced accident scenarios.

\section{PROPOSED GENERALIZED APPROACHES FOR ASSESSING THE NEED FOR HAZARD UPDATES AND RISK-RELATED ACTIONS}

Given the seven criteria described above, a proposed approach is described below for using that information to make a decision that will address DOE Order 420.1C for each SDC level (3 to 5). The approach takes into account several important considerations necessary for broad applicability of the methodology. The first consideration is that any approach that is useful across the range of nuclear facilities within the DOE complex must take into consideration the range of seismic design categories of SDC-3, SDC-4, and SDC-5. In Figures 1 to 3, the decision steps for exercising Criteria \#1 through \#7

\footnotetext{
${ }^{1}$ A HCLPF capacity is a ground motion level, beyond the design basis level, at which there is a high confidence that there is a low probability of failure (typically, considered to be failure probability of less than $5 \%$ with $95 \%$ confidence).
} 
defined earlier are summarized. As shown in Figures 1 to 3, the decision approach varies with the SDC category for the facility of interest. The diamond shapes indicate decision points and the criteria form the fundamental bases for the decisions made.

The second consideration is that the approach should take into account the multiple SSHAC Levels that are available for hazard assessment. As noted earlier, SL1 and SL2 studies, if conducted according to guidance, provide a sound method upon which to start the decision-making process. Typically, higher SSHAC Levels (SL3 and SL4) have been required to provide higher levels of regulatory assurance that the SSHAC goals have been attained. Such assurance is commonly linked to the safety significance of the facility, which is, in turn, is defined generally by the SDC category for the facility of interest. In this case, the methods also account for the regulatory assurance within a risk-informed process.

\section{Facilities Categorized as SDC-3}

The approach for an SDC-3 facility (Figure 1) starts by using the information from the SL1 or SL2 study to assess whether or not potentially significant new or updated data, models, or methods have become available since the existing PSHA study used to develop the design or licensing basis was conducted (Criterion \#1). If the answer is "no" (there are no new data, models or methods) then it is assumed that there would also be no change in the inputs to the hazard analysis or to the hazard results. Therefore, the action to be taken would be to document the approach used to identify new or updated information and the data, models, and methods that were considered and the basis for the conclusions drawn. If the answer to the first question is "yes" then an evaluation must be made as to whether or not the hazard inputs (i.e., the SSC and GMC models) would change from the previous PSHA (Criterion \#2). As before, if the answer to that question is "no" then the required action would be to document the assessments performed to evaluate the possible changes to the hazard input and the conclusions drawn.

If changes in the hazard inputs are anticipated, then changes in the calculated hazard value itself would next be calculated and considered (Criterion \#4). If no significant changes in hazard (within the levels of precision associated with such calculations) are anticipated, an assessment would next be made of whether or not the technical bases for the hazard and its various inputs have changed (Criterion \#3). If so, then, as emphasized in DOE-STD-1020-2012, it is prudent to continue the decision process. If neither the calculated hazard values nor the technical basis for the assessment have changed, the results and basis for the assessment should be documented and no further action is required.

The next decision step (Criterion \#5) is the comparison of the ground motions associated with SDC-3 AFE (i.e., $\mathrm{H}_{\mathrm{D}}=4 \times 10^{-4}$ in Table 1 ) with the existing design basis ground motions for the facility of interest. If the DBGM exceeds the SDC- $3 \mathrm{H}_{\mathrm{D}}$ ground motions, then it is proposed that the assessment process move on to Criterion \#6. If the DBGM is not greater than the SDC-3 motions, then it is recommended that additional risk and/or safety evaluations be performed using the estimated hazard from the SL1 or 2 study. There should also be an evaluation of the need for interim safety improvements until more detailed risk evaluations are conducted.

The next decision step (Criterion \#6) is a comparison of the existing DBGM for the facility with the GMRS for a SDC-3 category. If the DBGM for the facility exceeds the GMRS, then the decision process should be documented and no further actions are necessary. If, on the other hand, the GMRS exceeds the existing DBGM for the facility of interest, it is recommended that additional risk and/or safety evaluations be performed. 
For those cases where the DBGM has been found to be exceeded by either the applicable ground motions from the SDC-3 AFE design level or the GMRS, additional risk analyses, including either a SPRA or an SMA, should be conducted so that an evaluation can be made as to whether or not applicable risk objectives have been met. The first risk-informed decision point is Criterion \#7, in which the mean risk results and the appropriate risk insights are reviewed. The mean risk results in terms of failure probabilities of critical $\mathrm{SSC}_{\mathrm{e}} \mathrm{s}$ are compared to the target performance goal for a SDC-3 facility given in ASCE/SEI-43-05 (i.e., $\mathrm{P}_{\mathrm{F}}=1 \times 10^{-4}$ in Table 1). Examples of other appropriate risk insights to be considered may include a review of the risk-significant accident sequences and equipment to assess the degree of diversity and an assessment of the role of operator action to determine if plant procedures and training are sufficient.

For SDC-3 facilities, the decision of choosing between a SPRA or SMA approach may be straightforward as the potential accident scenarios and range of $\mathrm{SSE}_{\mathrm{e}}$ failures to be considered could be limited. For many SDC-3 facilities, there will be very limited considerations of non-seismic failures and operator actions. For these facilities, the seismic failure of passive components and/or structures has the biggest effect on the safety of the facility, and hence, on the ability to demonstrate that the performance target for the facility can be met. In such cases, the focus should be on identifying the components (and their pertinent failure modes) that affect the performance target and a SMA may be appropriate.

In the case where the risk objectives (e.g., target performance goals and qualitative objectives) are met and none of the risk insights raise a concern, the recommended action is to document the assessments made. No further actions are required. In the cases where the risk objectives are not met, it is recommended that a SL3 PSHA study be conducted. The results of the SL3 study will provide a highly defensible basis for new ground motion input values, for design modifications, and for any other associated engineering or licensing changes.

When risk objectives are not met, there are two possible cases anticipated. In the first case, the calculated risk values may exceed the performance goal by a large margin or risk insights may highlight an area of significant concern. In the second case, the risk targets may be exceeded by a small amount and the risk insights may not identify an area of immediate concern. In the first case, it may be prudent or required that an immediate safety concern be identified and compensatory actions determined, as appropriate. In the second case, where a smaller exceedance of the risk objectives is indicated, an immediate safety concern is less likely, although some regulatory frameworks may require some form of immediate action for any exceedance of the design basis earthquake ground motion. In both cases, the SL3 study will provide hazard values that can then be used to reevaluate risk in order to confirm earlier findings and/or to determine what additional actions, if any, are appropriate. Additional actions can include modifications, engineering changes, or procedural changes, as necessary. They can also include updates to the design, regulatory, or authorization bases, as necessary. 
INL/EXT-15-36510

Revision 1

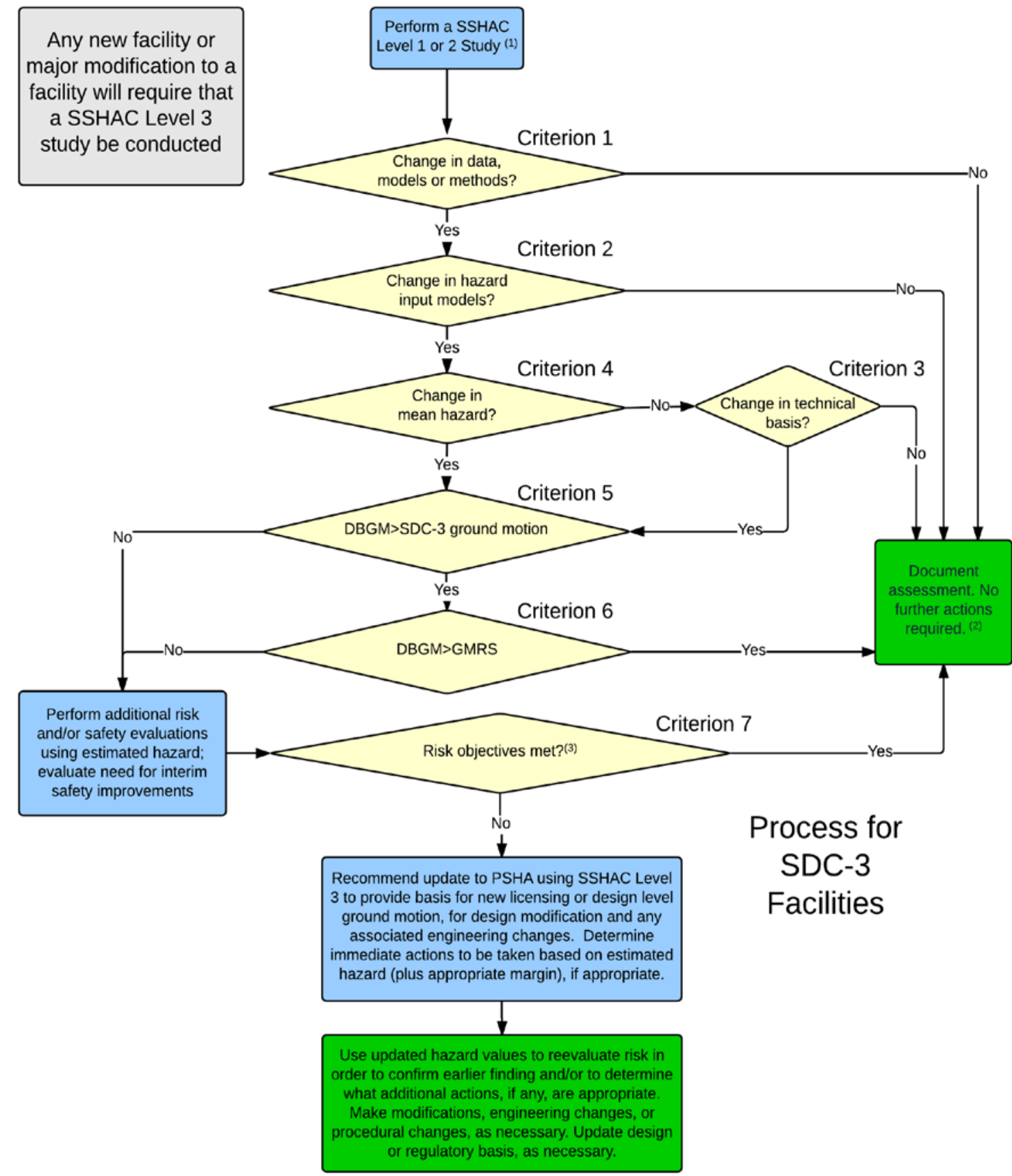

Notes:

1. The SSHAC level 1 or 2 study must include a documented in-process peer review. The resulting estimated hazard should be compared with the existing studies used to develop design or regulatory bases for the facility.

2. The estimated hazard and any risk-informed findings apply to this facility only and cannot be used for other facilities

3. See the report for discussion of the appropriate risk-related information to be considered

Figure 1. Chart of proposed methodology for a SDC-3 facility 


\section{Facilities Categorized as SDC-4}

The proposed decision process for SDC-4 facilities is shown in Figure 2. Consistent with a graded approach to safety, the criteria and steps in the process are essentially the same as for SDC-3, but the timing of actions is more rigorous and is designed to lead to higher levels of safety assurance. The steps, decision criteria, and recommended actions for the first six criteria are the same for SDC-4 as for SDC-3, with the exception that, if the response to all of the first six criteria is "yes" (leading to a new estimate of hazard) and the calculated GMRS exceeds the DBGM, then a SL3 study should be conducted. The SL3 PSHA will provide a defensible basis with high regulatory assurance for subsequent analyses that could involve design modifications and/or safety reviews. The results of the SL3 PSHA will provide input to a SPRA or SMA study.

For SDC-4 facilities, the choice between performing a SPRA and a SMA study involves several technical considerations beyond the potential savings in time and resources associated with an SMA. Current margin approaches are specifically developed for SDC-5 NPPs based on insights developed from light water reactor SPRAs. Current US SDC-5 NPP facilities typically have significant capability beyond their assessed HCLPF capacity, making the use of the HCLPF concept a viable approach for ensuring facility safety. For a SDC-4 facility, existing SMA approaches will need to be adapted to reflect the facility's unique considerations. This will involve identifying potential accident scenarios using a PRAstyle logic tree structure. For a facility involving complex accident scenarios, multiple systems, nonseismic failures, operator actions, and complex interactions, the choice of a SPRA is always the better choice unless substantial time and resource savings are realized and information necessary for riskinformed decision-making can clearly and demonstrably be obtained from a SMA study.

Once a SL3 PSHA has been conducted, the subsequent risk assessments are made. Risk insights and risk estimates are reviewed and evaluations as to whether or not the risk objectives have been met are conducted. The reviews are conducted in a manner that is identical to the SDC-3 methodology (Figure 1) except that the mean risk from the SPRA will be compared with the target performance goals for a SDC-4 facility $\left(\mathrm{P}_{\mathrm{F}}=4 \times 10^{-5}\right.$ according to Table 1$)$. If the mean risk is less than the performance goal and other risk objectives are met, then the recommended action is to clearly and completely document the actions taken and conclusions drawn. If the risk objectives are not met, then the subsequent actions are the same as those described for SDC-3 facilities. 
INL/EXT-15-36510

Revision 1

Any new facility or major modification to a facility will require that

a SSHAC Level 3 study be conducted
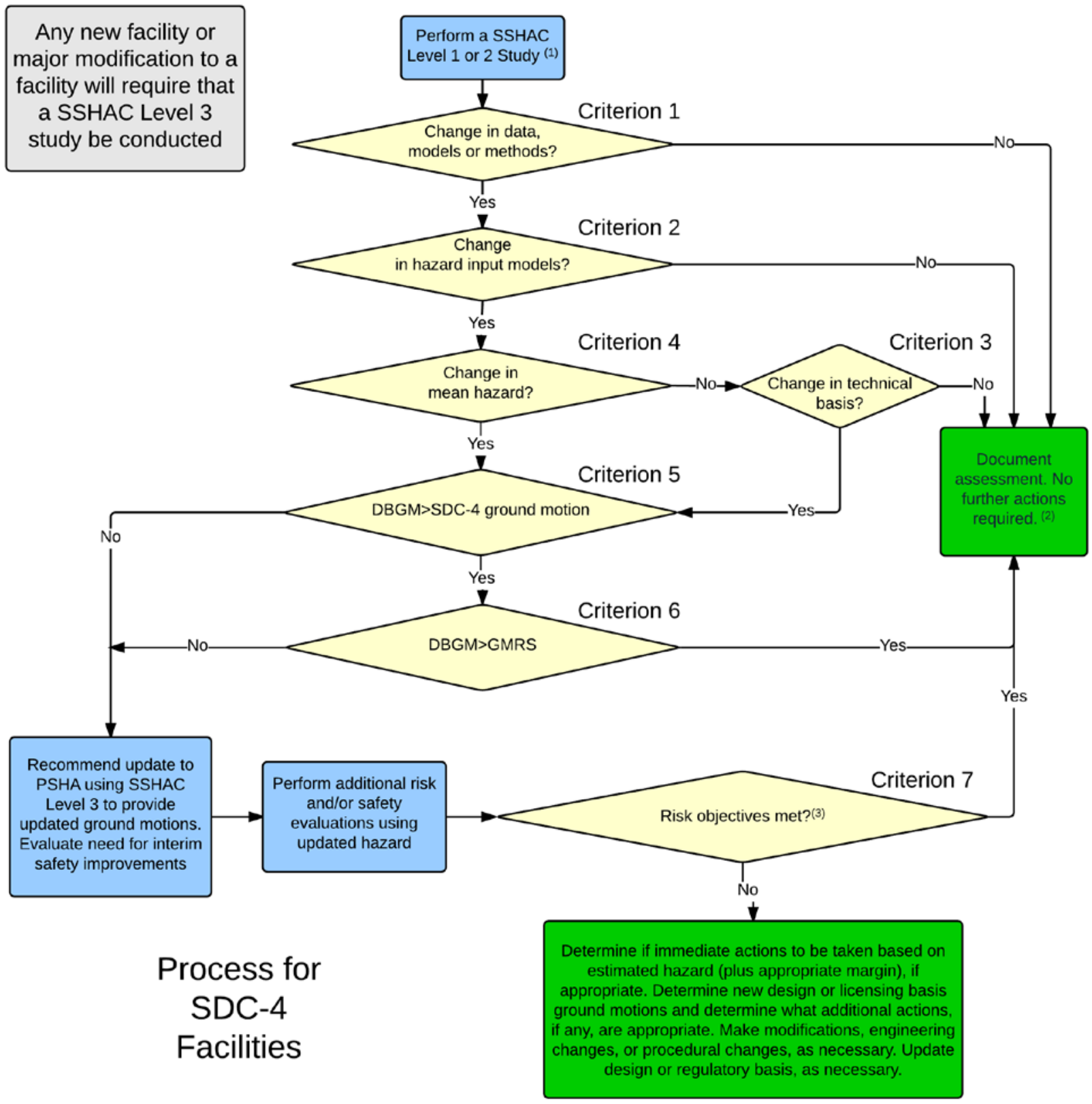

Notes:

1. The SSHAC level 1 or 2 study must include a documented in-process peer review. The resulting estimated hazard should be compared with the existing studies used to develop design or regulatory bases for the facility.

2. The estimated hazard and any risk-informed findings apply to this facility only and cannot be used for other facilities

3. See the report for a discussion of the appropriate risk-related information to be considered

Figure 2. Chart of proposed methodology for a SDC-4 facility 


\section{Facilities Categorized as SDC-5}

The proposed decision process for SDC-5 facilities is shown in Figure 3. Consistent with a graded approach, the criteria and decision steps in the process are essentially the same as for SDC-4, but the timing of the actions is more rigorous and is designed to lead to higher levels of safety assurance. In particular, the decision steps in the SHPRM for SDC-5 facilities are consistent with the approaches that have been implemented for NPPs in the US as part of the post-Fukushima requirements from the NRC as described in their 50.54(f) letter (NRC, 2012b) ${ }^{\mathrm{m}}$. The approach is also consistent with a risk-informed decision process that is endorsed by DOE, the Defense Nuclear Facilities Safety Board, the NRC, and the international nuclear community (IAEA, 2005 and IAEA, 2011).

As shown in Figure 3, if the application of the first four criteria results in "yes" findings, then it is recommended that a SL3 PSHA be conducted to replace the existing PSHA. The new PSHA will provide a higher level of regulatory assurance than the existing PSHA and will also provide a confident basis for subsequent analysis, as is appropriate for a SDC-5 facility. The mean hazard at the design $\mathrm{AFE}\left(\mathrm{H}_{\mathrm{D}}=1 \mathrm{x}\right.$ $10^{-4}$ in Table 1) from the new SL3 PSHA will be compared with the existing DBGM. The GMRS will be compared with the existing DBGM. If either the mean hazard at the AFE of interest or the GMRS exceeds the DBGM, then seismic risk studies, including a SPRA, will be conducted. The additional risk and/or safety evaluations using the updated hazard will be used to evaluate the need for interim safety improvements to be conducted in the near term.

As discussed earlier, two margin approaches exist for SDC-5 facilities: one is based on a "success path" approach and other is "SPRA-style" and is based on a fault tree/event tree approach. In general, the fault tree/event tree approach provides information that is similar to the information obtained from a SPRA. Guidance on these two approaches is available (See EPRI, 1991 and NRC, 2012d). As stated earlier, for a facility involving complex accident scenarios, multiple systems, non-seismic failures, operator actions, and complex interactions, the choice of a SPRA is always the better choice unless substantial time and resource savings are realized and necessary information for the risk-informed decision is demonstrably obtained from a margin type approach.

In Criterion \#7, the results of the seismic PRA or SMA will be compared to the target performance goals and other risk objectives for a SDC-5 facility to provide an indication of whether or not the facility has adequate levels of seismic safety. The comparison determines whether or not risk objectives have been met and the subsequent actions are consistent with those recommended for SDC-3 and SDC-4 facilities. Follow up actions may include flagging the assessed risk as an immediate safety concern or proceeding with changes in the DBGM, design bases, and/or retrofits that will lower the seismic risk from the facility to acceptable levels.

\footnotetext{
${ }^{m}$ This methodology is consistent with the approaches described in the NRC March 2012 letter (NRC, 2012b) with the exception that the acquisition of new site geotechnical data was not required by the NRC for any NPP site. Sites following the SHPRM to address the DOE Order should acquire new geotechnical data through site investigation if the available information for the site is not consistent with current best practice.
} 
INL/EXT-15-36510

Revision 1

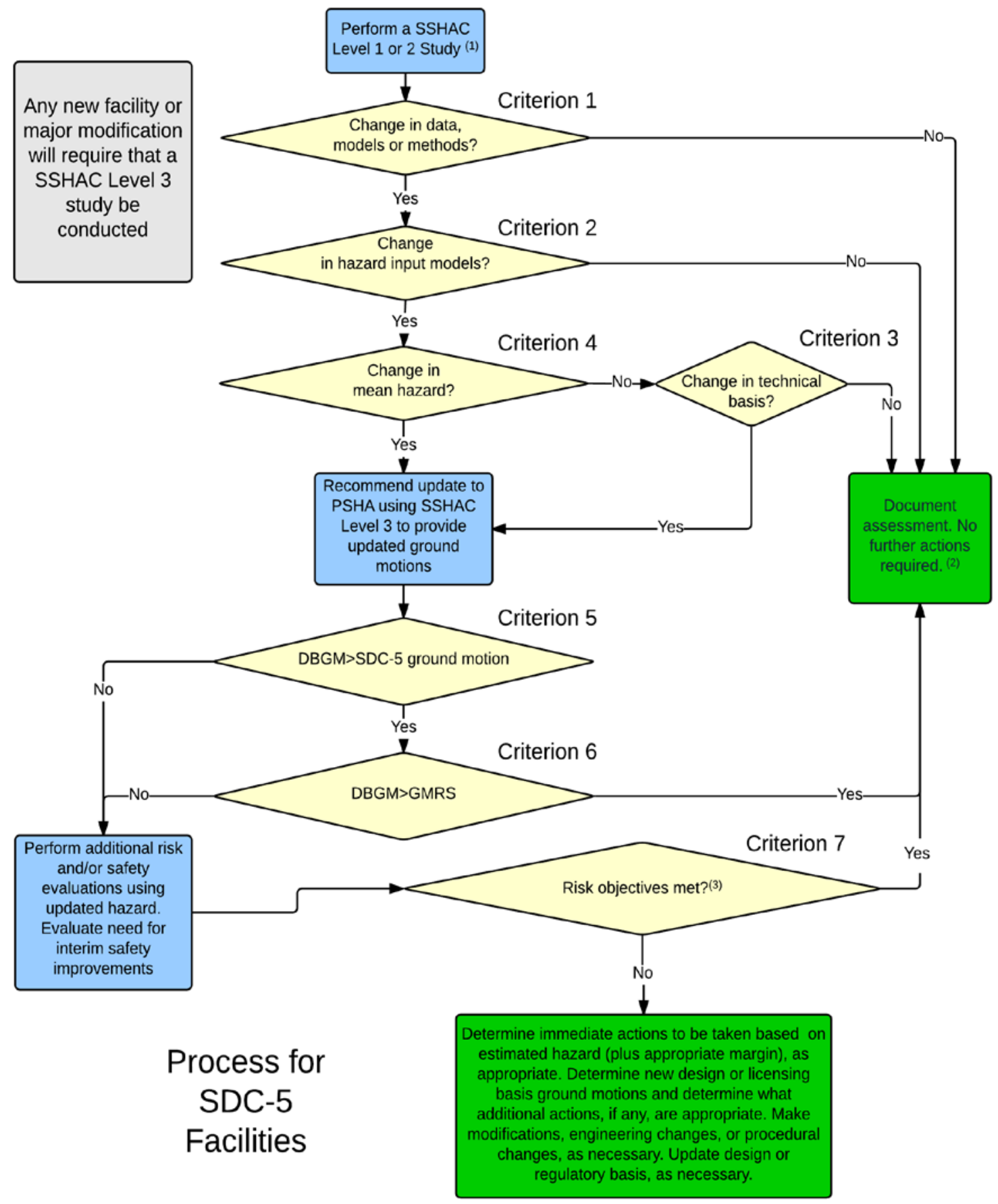

Notes:

1. The SSHAC level 1 or 2 study must include a documented in-process peer review. The resulting estimated hazard should be compared with the existing studies used to develop design or licensing bases for the facility.

2. The estimated hazard and any risk-informed findings apply to this facility only and cannot be used for other facilities.

3. See the report for discussion of the appropriate risk-related information to be considered.

Figure 3. Chart of proposed methodology for a SDC-5 facility 
INL/EXT-15-36510

Revision 1

\section{INL Actions to Address Criteria}

The INL Seismic Risk Assessment Project is aimed at conducting the activities that are necessary for applying the methodology described in this document. The activities in the Project are specific to the INL site and facilities. However, it is anticipated that the SHPRM identified in this document will have general applicability to other DOE nuclear facilities required to comply with DOE Order 420.1C. The activities being conducted at INL are shown in Figure 4 and consist of a SL1 PSHA and various hazard and riskassessment related activities. One result of these activities will be a determination as to whether or not a new SL3 PSHA study is needed to replace the existing PSHA for the facilities currently under review. New facilities or major modification of an existing facility would require a SL3 study be conducted. The activities will also be used to determine actions that can or should be taken at the INL facilities to effectively enhance seismic safety.

The SL1 methodology in NUREG-2117 provides an organized, structured, and documented approach for addressing several of the updating criteria in DOE Order 420.1C. The TI Team is responsible for identifying all relevant new data, models, and methods that have become available since the most recent PSHA. The most recent PSHA study for INL was conducted in 1996, with some updates to the GMC components of the model conducted in 2000. The data, models, and methods used in that earlier study will be compared with those developed for the SL1 (Criterion \#1). Based on the available data, models, and methods, the TI Team will then develop revised SSC and GMC models that will be the primary inputs to the SL1 or SL2 PSHA.

These models and other inputs to the hazard analysis will be compared with those developed for the previous hazard studies to identify any significant changes (Criterion \#2). For example, the manner in which the fault sources of the Lost River fault system have been characterized for their recurrence behavior and rupture segmentation will be compared with current information. In terms of the GMC, the use of applicable ground motion prediction equations will be compared, as will the tailoring of those models to be compatible with the specific shear wave velocity and kappa values for the sites of interest. Because the SL1 study is following a SSHAC process, a key aspect of the study will be to document the technical justification for all of the assessments made by the TI Team, including the quantification of uncertainties. This documentation includes the justification for all conceptual models and parameter values included in the logic trees, and the approaches taken to properly represent the center, body, and range of technically defensible interpretations. It will then be possible to compare the technical bases for the SL1 study with those bases relied upon for the 1996/2000 studies (Criterion \#3) to identify any significant differences.

Once the SL1 PSHA is completed, the mean hazard results (mean hazard curves) can be compared with those developed for the 1996/2000 studies (Criterion \#4). These comparisons will be for a full range of AFEs and at structural frequencies of interest for the facility. In the evaluation of whether or not the changes in hazard are significant, consideration will be given to the typical precision estimates for seismic hazard calculations. The seismic hazard results will also be used to assess the UHS associated with the appropriate mean hazard exceedance probability (Table 1) for the SDC of the facility. This UHS will be compared with the Authorization Basis Earthquake ground motion that exists for the facility of interest (Criterion \#5).

An important contribution to the updating criteria will come from risk assessment studies being conducted for the facilities at INL currently under review. These studies include assessment of the fragilities for the $\mathrm{SSC}_{\mathrm{e}} \mathrm{s}$, and development of a systems model that describes the manner in which the 
$\mathrm{SSC}_{\mathrm{e}} \mathrm{s}$ interact in accident sequences. The risk studies will use the full hazard distribution from the SL1 PSHA, including the mean and fractiles hazard values over a broad range of AFEs down to $10^{-7}$. As indicated in DOE-STD-1020-2012 (Section 3.6), provisions of ASCE/SEI 43-05 shall be used for determining $\mathrm{SSC}_{\mathrm{e}}$ capacity to withstand the seismic demands combined with other applicable concurrent loads. As part of the risk studies, consideration will be given to facility-specific information at INL. Any information from other nuclear facilities related to the seismic parameter $\mathrm{R}_{\mathrm{p}}$ that exists for SDC-3 and SDC-4 facilities will also be considered.

Given that a GMRS level and risk-informed methodology are defined for SDC-3 and SDC-4 facilities, the SL1 PSHA can be used to calculate the GMRS at INL facilities. Based on the methodology given in ASCE/SEI-43-05, the GMRS will include design factors based on both the AFE of the hazard and the slope of the hazard curves (Kennedy, 2011). The GMRS will then be compared with the existing DBGM for each of the facilities (Criterion \#6). When the mean seismic risk has been calculated for an entire facility, it will be compared with the target performance goals given in ASCE/SEI-43-05 shown in Table 1 (Criterion \#7). Other risk insights will also be reviewed to confirm that risk objectives are met. ${ }^{n}$

\footnotetext{
${ }^{\mathrm{n}}$ At this time, this Independent Panel has not reviewed any proposed specific risk objectives to be used for decision making at INL facilities beyond the quantitative objectives described in Table 1. Other objectives related to risk insights have not been discussed. As noted in the discussion of Criterion \#7 earlier, the risk-informed objectives to be used in decision making are to be developed by INL management, along with their DOE stakeholders and any other bodies with regulatory authority. However, this Panel would provide input on any proposed risk objectives if asked to do so.
} 


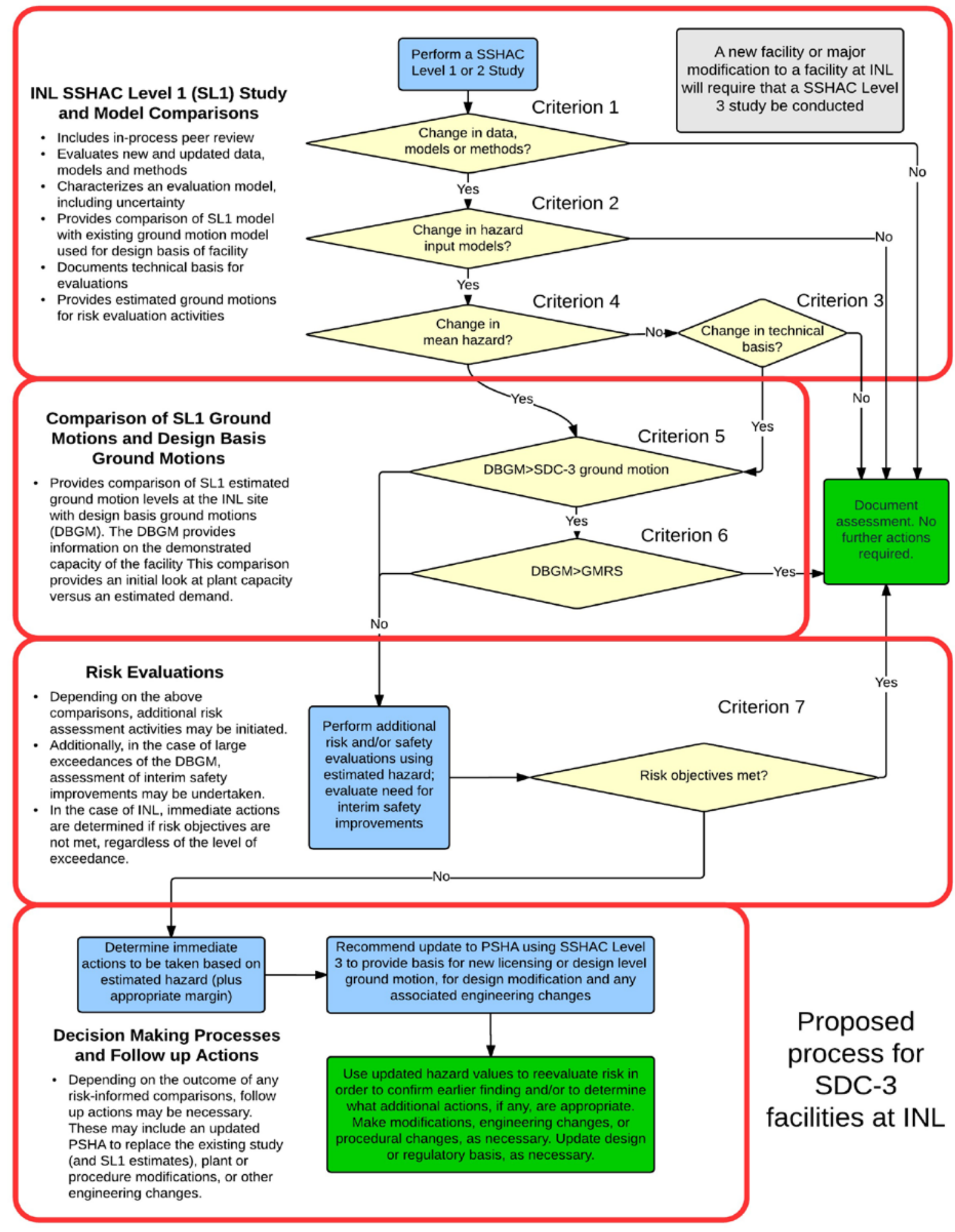

Figure 4. Chart showing INL activities intended to meet DOE Order 420.1C 


\section{CONCLUSIONS}

In addition to the proposed SHPRM outlined in this document, the Panel also offers its advice regarding the implementation of the methodology for facilities in the future. The overall goal of DOE Order $420.1 \mathrm{C}$ is facility safety and the desire to ensure that the seismic and other natural phenomena hazard assessments are evaluated periodically and systematically for their validity relative to current knowledge. It is understood that our understanding of seismic hazards evolves with time, and data, models, and methods can likewise change. This can lead to the potentially unsafe condition in which the design bases for a particular nuclear facility are no longer consistent with current knowledge and are potentially non-conservative. Even if the calculated hazard has not changed, a significant change in the technical bases that underpin the seismic hazard model can undermine the credibility of the seismic safety determination for a given nuclear facility. Although DOE-STD-1020-2012 provides valuable guidance, experience has shown that the manner in which DOE Order $420.1 \mathrm{C}$ is addressed for seismic hazard can vary. Therefore, key goals of this proposed methodology are to provide structure and consistency to the methodology used, and to provide a risk-informed, graded approach that takes into account the risk significance of the facility of interest. As the SHPRM is applied at DOE facilities, an effort to consistently glean lessons and understand the risk information developed would benefit the later application of the methodology.

It is important to note that the steps, decisions, and actions found in this document should be viewed as the "minimum" required for any given SDC level. For example, the approach described in this document might recommend that an updated SL3 PSHA be considered only after multiple evaluations of new information and changes in seismic hazard are conducted. However, a decision to proceed with such a PSHA update may be made at any time prior to conducting all of the suggested steps.

Another important consideration in the exercise of the SHPRM described in this document is that many of the decision criteria are qualitative and subject to interpretation and expert judgment. This is the case for many of the criteria already provided in the DOE-STD-1020-2012 (Criteria \#1 through 4), so it is not unexpected. The burden in applying these criteria and on justifying the outcome is on the team doing the evaluations. As such, it is critical that the documentation at every step is clear and complete and includes a tractable discussion of the technical justification for all decisions. This applies equally to cases where application of the decision criteria leads to a finding that additional work is necessary or that additional work is not necessary. It is also recognized that even the more quantitative decision criteria, such as the comparisons of hazard and risk measures with design bases or performance goals, also require complete technical justification and documentation. Because expert judgment must be applied throughout the process, peer review of the hazard assessment, risk assessment, and overall risk-informed SHPRM process is also strongly recommended. 
INL/EXT-15-36510

Revision 1

\section{REFERENCES}

ANSI/ANS (American National Standards Institute/American Nuclear Society). 2004 (Reaffirmed 2010). Categorization of Nuclear Facility Structures, Systems, and Components for Seismic Design. ANSI/ANS-2.26-2004; R2010, Le Grange Park, Illinois.

ANSI/ANS (American National Standards Institute/American Nuclear Society). 2008. Probabilistic Seismic Hazard Analysis. ANSI/ANS-2.29-2008, Le Grange Park, Illinois.

ASCE/SEI 43-05, Seismic Design Criteria for Structures, Systems and Components in Nuclear Facilities, 2005, Structural Engineering Institute of the American Society of Civil Engineers.

ASME/ANS (American Society of Mechanical Engineers/American Nuclear Society). 2013. Standard for Level 1/Large Early Release Frequency Probabilistic Risk Assessment for Nuclear Power Plant Applications. Standard ASME/ANS RA-Sb-2013.

DOE (U.S. Department of Energy). 2012a. Facility Safety. DOE Order 420.1C, Washington, D.C.

DOE (U.S. Department of Energy). 2012b. DOE Standard, Natural Phenomena Hazards Analysis and Design Criteria for DOE Facilities. DOE-STD-1020-2012, Washington, D.C.

DOE (U.S. Department of Energy). 2013. DOE Standard, Development of Probabilistic Risk Assessments for Nuclear Safety Applications. DOE-STD-1628-2013, Washington, D.C.

EPRI (Electric Power Research Institute). 1991. A Methodology for Assessment of Nuclear Power Plant Seismic Margin. EPRI Report NP-6041-SL, Revision 1, Palo Alto, Ca. 1991.

EPRI (Electric Power Research Institute). 2013a. Screening, Prioritization and Implementation Details (SPID) for the Resolution of Fukushima Near-Term Task Force Recommendation 2.1: Seismic. EPRI Report 1025287, February 2013, Palo Alto, CA

EPRI (Electric Power Research Institute). 2013b. Seismic Evaluation Guidance: Augmented Approach for the Resolution of Fukushima Near-Term Task Force Recommendation 2.1: Seismic. EPRI Report 3002000704. May 2013. Palo Alto, CA.

IAEA (International Atomic Energy Agency). 2005. Risk informed regulation of nuclear facilities: Overview of the current status. IAEA-TECDOC-1436, Vienna.

IAEA (International Atomic Energy Agency). 2011. A Framework for Integrated Risk- Informed Decisions Making Process. Report INSAG-25, IAEA, Vienna.

INL (Idaho National Laboratory). 2015. Project Execution Plan PLN-31287: INL Seismic Risk Assessment Project, Idaho National Laboratory Report, Idaho Falls, 2015.

Kennedy, R. P. (2011). Performance-goal based (risk informed) approach for establishing the SSE site specific response spectrum for future nuclear power plants. Nuclear Engineering and Design, 241(3), 648-656.

NRC (U.S. Nuclear Regulatory Commission). 1985. An Approach to the Quantification of Seismic Margins in Nuclear Power Plants. NUREG/CR-4334, August 1985. Washington, DC.

NRC (U.S. Nuclear Regulatory Commission). 1997. Recommendations for Probabilistic Seismic Hazard Analysis: Guidance on Uncertainty and the Use of Experts. NUREG/CR-6372, two volumes, US Nuclear Regulatory Commission, Washington, D.C. 
INL/EXT-15-36510

Revision 1

NRC (U.S. Nuclear Regulatory Commission). 2003. Site Investigations for Foundations of Nuclear Power Plats. Regulatory Guide 1.132, Washington, D.C.

NRC (U.S. Nuclear Regulatory Commission). 2007. A Performance-Based Approach to Define the SiteSpecific Earthquake Ground Motion. Regulatory Guide 1.208, Washington, D.C.

NRC (U.S. Nuclear Regulatory Commission). 2009. An Approach for Determining the Technical Adequacy of Probabilistic Risk Assessment Results for Risk-Informed Activities. Regulatory Guide 1.208, Washington, D.C.

NRC (U.S. Nuclear Regulatory Commission). 2011. An Approach for Using Probabilistic Risk Assessment in Risk-Informed Decisions on Plant-Specific Changes to the Licensing Basis, Regulatory Guide 1.174, U.S. Nuclear Regulatory Commission, Washington, DC.

NRC (U.S. Nuclear Regulatory Commission). 2012a. Practical Implementation Guidelines for SSHAC Level 3 and 4 Hazard Studies. NUREG-2117, Rev. 1, Washington, D.C.

NRC (U.S. Nuclear Regulatory Commission). 2012b. Central and Eastern United States Seismic Source Characterization for Nuclear Facilities. NUREG-2115, Washington, D.C.

NRC (U.S. Nuclear Regulatory Commission). 2012c. Request for Information Pursuant to Title 10 of the Code of Federal Regulations 50.54(f) regarding Recommendation 2.1, 2.3, and 9.3, of the Near-Term Task Force Review of Insights from the Fukushima Dai-Ichi Accident. Dated March 12, 2012, Washington, D.C.

NRC (U.S. Nuclear Regulatory Commission). 2012d. Interim Staff Guidance on Performing a Seismic Margin Assessment in Response to the March 2012 Request for Information Letter. JLD-ISG-12-04, Issued September 4, 2012. Washington, D.C. 